\title{
Synthesis and Characterization of Shape Memory Polyurethanes
}

\author{
Míriam Sáenz-Pérez ${ }^{1,2 *}$, José Manuel Laza ${ }^{1}$, Jorge García-Barrasa ${ }^{2}$, Luis Manuel León ${ }^{1}$ and José \\ Luis Vilas ${ }^{1}$ \\ 1 Macromolecular Chemistry Research Group. Dept. of Physical Chemistry. Faculty of Science and \\ Technology. University of the Basque Country (UPV/EHU), Leioa 48940, Spain. E-Mail: \\ josemanuel.laza@ehu.es_(J.M.L.), luismanuel.leon@ehu.eus (L.M.L.) and joseluis.vilas@ehu.eus \\ (J.L.V.) \\ 2 The Footwear Technology Center of La Rioja, Calle Raposal 65, Arnedo 26580, Spain; E-Mail: \\ jgarcia@ctcr.es_(J.G.) \\ * M. Sáenz-Pérez; E-Mail: msaenz@ctcr.es; Tel.: +34 946015534.
}

Published: 4 December 2015

\begin{abstract}
Shape memory polymers (SMPs) have attracted extensive attention from basic and fundamental research to industrial and practical applications because they have emerged as a cheap and efficient alternative to well-known metallic shape-memory alloys. Among them, shape memory polyurethanes (SMPUs) own different applications such as the textile finishing, adhesives, coatings, automotive, furniture, construction, and thermal insulation and footwear industries, due to it can be synthesized with different types of molecular architectures by manipulating their composition and choosing properly the chemical structure of their components. In this work, the synthesis and characterization of shape memory polyurethanes, based on two-step polymerization, is reported. The hard segment of SMPU was composed of diisocyanate and a chain extender. On the other hand, the soft segment was prepared by polyols with different molecular weights. Depending on the structure of the synthetized polyurethanes, the materials presented different properties. Thermal characterization was performed by means of Differential Scanning Calorimetry (DSC) and Thermogravimetric Analysis (TGA). Furthermore, mechanical properties and shape memory effect were also determined by Dynamic Mechanical Analysis (DMA) and Thermo-Mechanical Analysis (TMA).
\end{abstract}

Keywords: shape memory behavior; polyurethane; mechanical properties; thermal properties. 


\section{Introduction}

Shape memory polymers (SMPs) present the ability of modifying their shape in a predefined manner in response to externally imposed stimuli. A deformation-induced temporary shape is transformed to an initial equilibrium configuration defined by the chemical or physical crosslinkings within the polymer. SMPs are cheap, easy processing, light, could be deformed to high strains and high recovery ratios are achieved, in contrast to shape memory alloys. Up to date, light, thermal, electrical, magnetic stimuli have been mainly used for trigger the shape-memory effect in polymeric materials ${ }^{1,2}$.

Usually, shape memory process consists of two different phases known as "programming" and "recovery". During the programming, the material is deformed above the softening temperature, where the conformational entropy of the material is decreased. Subsequently the material is cooled to temperatures below the segmental transition under constrained conditions to reach the "temporary shape" owing to the reduced molecular mobility at temperatures below transition temperature $\left(T_{\text {trans }}\right)^{3,4}$. Finally, the material recovers its initial permanent "fixed shape" upon the application of the external stimulus which triggers the shape memory effect (Figure 1). Depending on their microstructure and chemical nature several classes of SMPs could be found. Among all the available types of materials showing a shapememory effect, shape memory polyurethanes (SMPUs) have shown suitable physicomechanical properties to be used in applications as varied as stents, microactuators and wrinkle free fabrics among others ${ }^{5,6}$.

Though extensive work has been devoted in developing SMPUs, little attention has been paid in understanding how the chain microstructure affects the shape-memory behavior and mechanical properties of the resulting material. In this framework, this work deals with the synthesis and physic-mechanical characterization of toluene 2,4-diisocyanate (TDI) based SMPUs. Transition temperatures have been determined by Differential Scanning Calorimetry (DSC) and Dynamic Mechanical Thermal Analysis (DMTA). Thermomechanical programming experiments were carried out to examine the shape-memory effect of developed materials. In overall, results reveal a marked influence of the soft-hard segments over the transition temperature and shape-memory effect of TDIbased polyurethanes.

\section{Results and Discussion}

\subsection{Thermogravimetric Analysis (TGA)}

The representative TGA curves obtained from SMPUs with different molar ratio are shown in Figure 2 and the initial decomposition temperatures, $T_{i}$, are listed in Table 1.

It is generally accepted that the thermal degradation process in polyurethanes is a twostage or three-stage decomposition, which mainly depends on the chemical structure, and the composition of polyols, diisocyanates, and chain extenders ${ }^{7,8}$. The three synthetized polyurethanes display typical two-stage degradation. The first one may be attributed to the PU hard segments, whereas in the second stage the degradation is caused by the soft segments. The obtained results show good thermal stability for the three samples, indicating that the choice both the diisocyanate and the butanodiol influence on the thermal decomposition of polyurethanes. 
On the other hand, the residue of the SMPUs increased as the molar relation between diisocyanate and butanodiol increase. This may be due in part to favorable interactions between the hard domain interface and the liquid crystalline phase $\mathrm{e}^{9,10}$.

\begin{tabular}{cccc}
\hline Samples & $T_{i}\left({ }^{\circ} \mathrm{C}\right)$ & $\begin{array}{c}T_{g, D S C} \\
\left({ }^{\circ} \mathrm{C}\right)\end{array}$ & $\begin{array}{c}T_{g, D M T A} \\
\left({ }^{\circ} \mathrm{C}\right)\end{array}$ \\
\hline SMPU-3.5 & 279 & -1.2 & 44.6 \\
SMPU-4.5 & 275 & 19.8 & 58.1 \\
SMPU-5.5 & 285 & 29.5 & 62.9 \\
\hline
\end{tabular}

Table 1. Thermal properties of synthetized

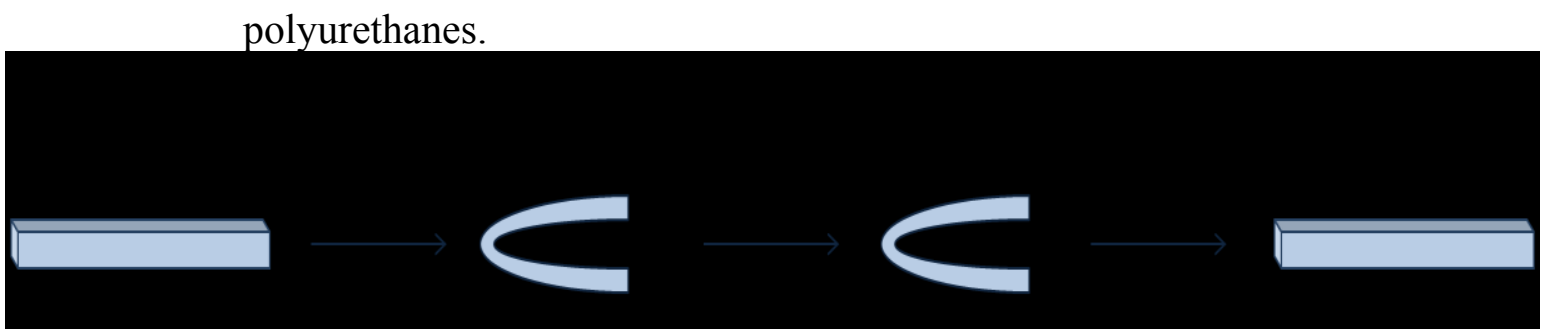

Figure 1. Schematic representation of the mechanism of the shape memory effect.

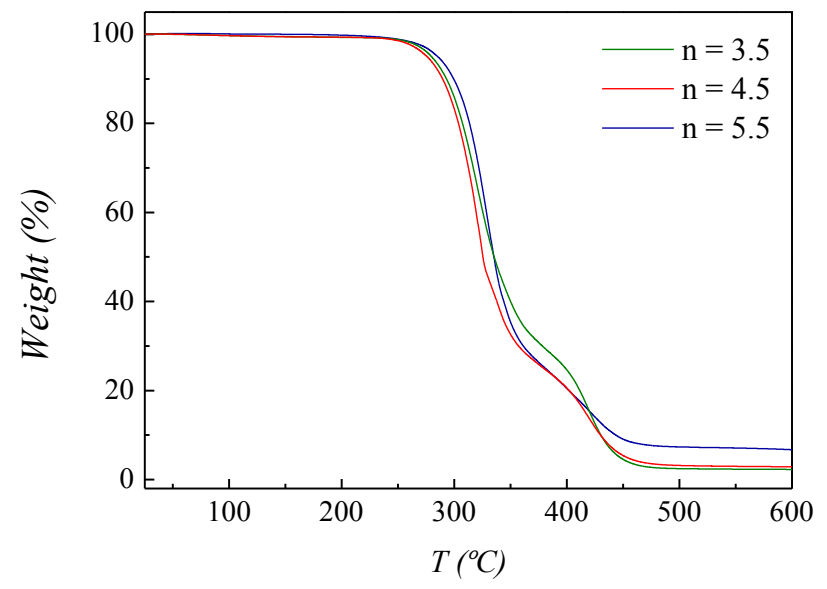

Figure 2. TGA curves for synthetized polyurethanes.

\subsection{Differential Scanning Calorimetry (DSC)}

The DSC scans of the SMPUs are shown in Figure 3 and the measured glass transition temperatures, $T_{g}, D S C$, are summarized in Table 1. DSC results show that as increase the hard segment content (higher $\mathrm{n}$ ), higher is the glass transition temperature ${ }^{11,12}$. This suggests that hard segment interaction among polymeric chains were strengthened at low hard segment content, due to these hard segments can achieve a more well-oriented position within the polymeric structure.

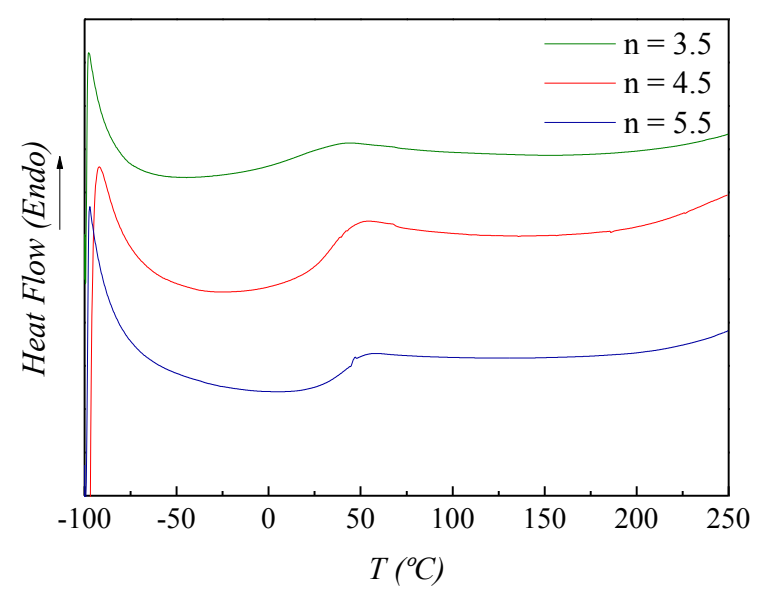

Figure 3. DSC curves for synthetized polyurethanes. 


\subsection{Dynamic Mechanical Thermal Analysis} (DMTA)

DMTA analysis is a sensitive method to study the thermomechanical behavior of polymers. The major peak in the loss factor, $\tan \delta$, is usually used to designate $T_{g}$. This peak corresponds with a sharp drop in the storage modulus $\left(E^{\prime}\right)$, so this is also an important parameter in order to evaluate the structure-property relationship of these materials.

Figure 4 shows the variation of the storage modulus $\left(E^{\prime}\right)$ and the loss factor, $\tan \delta$, as a function of the temperature for the synthetized polyurethanes, and in Table 1 are showed the

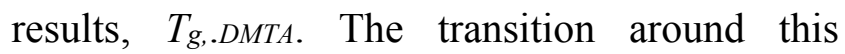
temperature was ascribed to the glass transition of the hard segment phase ${ }^{13,14}$. Therefore, as increase the hard segment content higher is the glass transition temperature, which is in agreement with the DSC results.

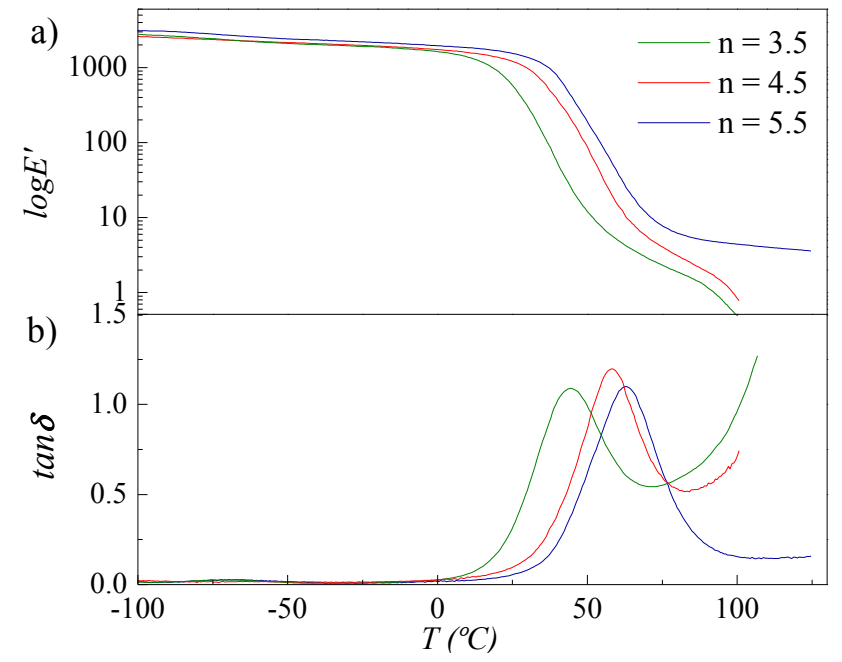

Figure 4. DMTA curves for synthetized polyurethanes: a) storage modulus $\left(\log E^{\prime}\right)$; and b) loss factor $(\tan \delta)$.

\subsection{Shape Memory Behavior}

Shape memory effect can be measured qualitatively and quantitatively. In Figure 5, it can be observed that synthetized polyurethanes have shape memory effect. Regarding thermallyactivated shape-memory properties, soft segments will be responsible for shape fixity, acting as the switching segments, while hard segments will be responsible for shape recovery, determining the permanent shape ${ }^{15}$.
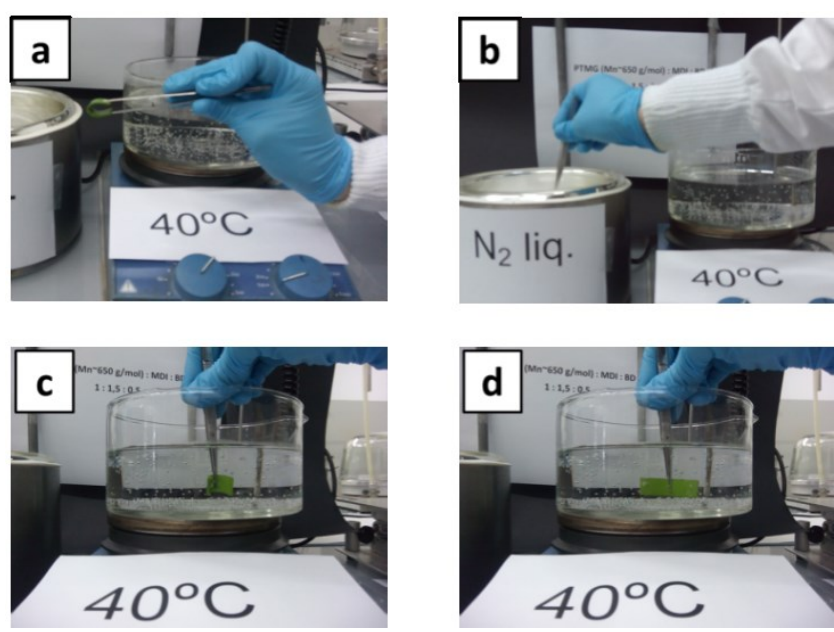

Figure 5. Images of behavior of SMPU. a)

Deformation, b) Shape Fixation, c)

Recovery, d) Original shape.

The thermally activated shape memory behavior of SMPUs is shown in Figure 6. Table 2 summarized the values obtained of fixity ratio $\left(R_{f}\right)$ and shape recovery ratio $\left(R_{r}\right)$ which were calculated employing Eqs 1 and 2. The shape memory behavior of SMPUs represents almost complete strain fixing (more than 87\%) or recovery $(99 \%)$.

Table 2. Shape fixing and recovery efficiencies

\begin{tabular}{ccc}
\multicolumn{3}{c}{ of SMPUs. } \\
\hline Samples & $R_{f}(\%)$ & $R_{r}(\%)$ \\
\hline SMPU-3.5 & 89.9 & 99.8 \\
SMPU-4.5 & 98.9 & 99.7 \\
SMPU-5.5 & 87.2 & 100 \\
\hline
\end{tabular}




\section{Materials and Methods}

\subsection{Materials}

Polytetramethylene glycol (PTMG, $M_{n}=650$ $\mathrm{g} \cdot \mathrm{mol}^{-1}$ ) used as polyol, and toluene 2,4diisocyanate (TDI), were purchased by Sigma Aldrich and were used as received. Moreover, 1,4-butanediol (BD, Sigma Aldrich), chain extender, was dried under vaccum for $3 \mathrm{~h}$ at $65^{\circ} \mathrm{C}$ before use.
3.2. Synthesis of shape memory polyurethanes

All the SMPUs were synthesized by a twostep method varying the hard-segment content. The SMPUs were prepared by reaction of stoichiometric amount of polyol / diisocyanate / chain extender with block ratios of $1: n+1: n$ (where $n$ is between 3.5 and 5.5), view Table 3 . The reaction scheme for the synthesis is shown according to the route outlined in Figure 7.

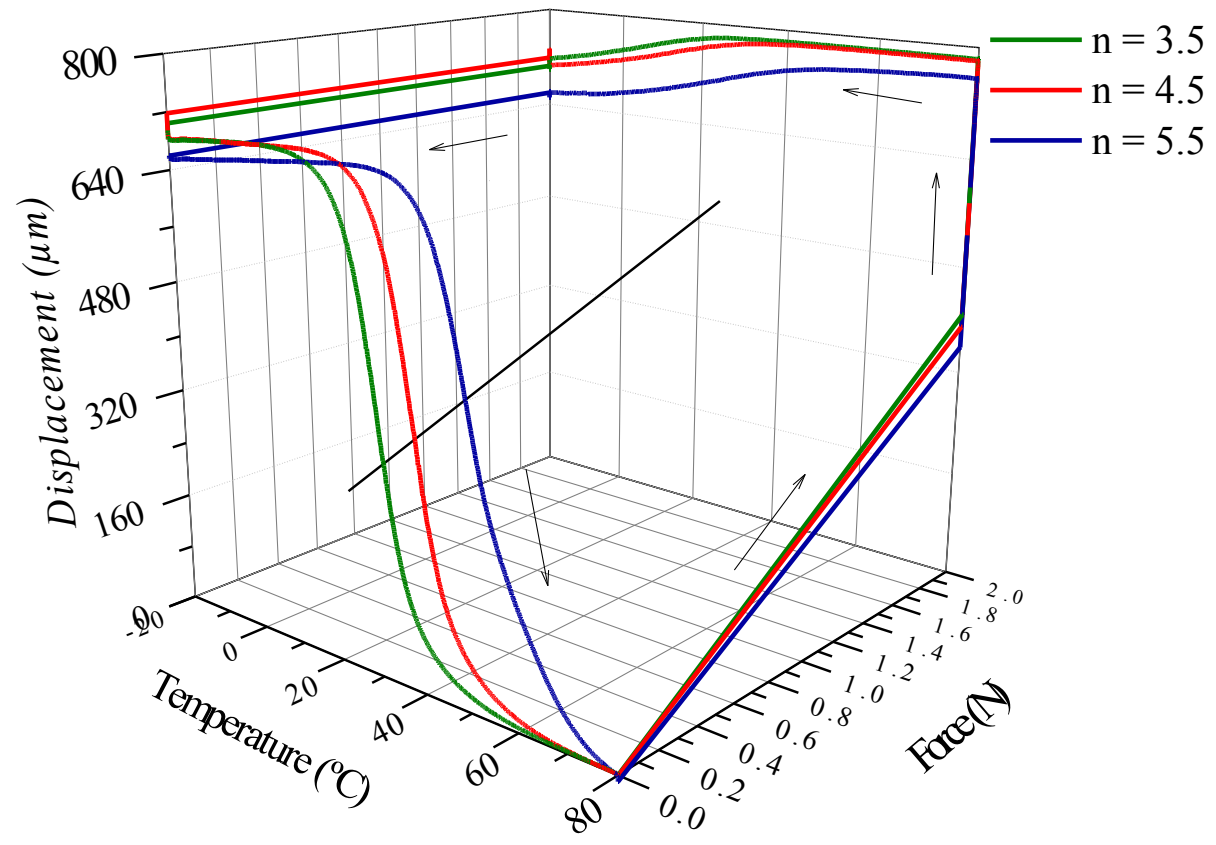

Figure 6. Three-dimensional thermomechanical cycle for synthetized polyurethanes.

On the other hand, the soft segment was prepared by polytetramethylene glycol (PTMG), $M_{n}=650$

Table 3. Polyurethane composition.

\begin{tabular}{cccc}
\hline \multirow{2}{*}{ Samples } & \multicolumn{3}{c}{ Composition of polyurethane } \\
& PTMG & TDI & BD \\
\hline SMPU-3.5 & 1 & 4.5 & 3.5 \\
SMPU-4.5 & 1 & 5.5 & 4.5 \\
SMPU-5.5 & 1 & 6.5 & 5.5 \\
\hline
\end{tabular}

On the one hand, the hard segments of SMPU were composed of toluene 2,4-diisocyanate (TDI) and a chain extender, 1,4-butanediol (BD). $\mathrm{g} \cdot \mathrm{mol}^{-1}$.

The synthesis was carried out in a $150 \mathrm{~mL} 5$ neck round-bottom flask heated at $70^{\circ} \mathrm{C}$ in an oil bath, equipped with a mechanical stirrer and a nitrogen inlet. In the first step, the polyol, polytetramethylene glycol, was added into the dry reactor. After $30 \mathrm{~min}$ with nitrogen atmosphere, TDI was added dropwise. The reaction continued at $70^{\circ} \mathrm{C}$ for $2 \mathrm{~h}$ to obtain $-\mathrm{NCO}$ terminated prepolymer, under a vigorous flow of 
nitrogen to prevent the reaction of the isocyanate groups with air moisture. In the second step, the chain extender, BD, was added dropwise into the reaction system. The reaction mixture was continuously stirred during approximately 2 minutes until a significant increase in viscosity was detected. The viscous mixture was poured into a preheated stainless steel mold and placed in a hydraulic press under pressure at $100^{\circ} \mathrm{C}$ overnight to obtain the final polymer.

\subsection{Characterization techniques}

Thermal properties of all samples were measured by Differential Scanning Calorimetry (DSC 822e from Mettler Toledo) to identify thermal actuation temperatures. The transition temperature of shape memory effect $\left(T_{\text {trans }}\right)$ was defined from glass transition temperature measured in the second heating cycle $\left(T_{g}, D S C\right.$ in Table 1). Samples in aluminium pans were characterized under constant nitrogen flow (50 $\left.\mathrm{mL} \cdot \mathrm{min}^{-1}\right)$. First, the PU samples were equilibrated at $-100^{\circ} \mathrm{C}$, and then heated at a rate of $10^{\circ} \mathrm{C} \cdot \mathrm{min}^{-1}$ from -100 to $250^{\circ} \mathrm{C}$. In this first cycle, the thermal history of the sample was erased. It was then cooled down to $-100^{\circ} \mathrm{C}$ at a cooling rate of $10^{\circ} \mathrm{C} \cdot \mathrm{min}^{-1}$. Subsequently, a second heating scan to $250^{\circ} \mathrm{C}$ was conducted at the same heating rate. In all cases samples around $10-15 \mathrm{mg}$ were used.

Thermal degradation behaviour was studied by Thermogravimetric Analysis (TGA METTLER TOLEDO 822e) in alumina pans under nitrogen atmosphere by heating the samples $(10-15 \mathrm{mg})$ from room temperature to $800^{\circ} \mathrm{C}$ at $10^{\circ} \mathrm{C} \cdot \mathrm{min}^{-1}$.

Dynamic Mechanical Thermal Analysis (DMTA) was performed on a Mettler-Toledo
DMA1 analyzer in tensile mode. $1.5 \mathrm{~mm}$ thick, 6 $\mathrm{mm}$ wide and $10 \mathrm{~mm}$ long specimens were used. Curves displaying storage modulus $\left(E^{\prime}\right)$ and the loss factor $(\tan \delta)$ were recorded in the range of -100 to $150^{\circ} \mathrm{C}$ at a heating rate of $3^{\circ} \mathrm{C} \cdot \mathrm{min}^{-1}$ and at a deformation frequency of $10 \mathrm{~Hz}$ and displacement of $20 \mu \mathrm{m}$, which is found within the Linear Viscoelastic Region (LVR) of synthetized SMPUs.

For Thermo-Mechanical Analysis (TMA) measurements, samples were conducted on a Mettler Toledo DMA1 in the temperature range of $-20-80^{\circ} \mathrm{C}$ at a heating rate of $4^{\circ} \mathrm{C} \cdot \mathrm{min}^{-1}$. Rectangular samples of about $10 \mathrm{~mm}$ x $6 \mathrm{~mm} \times$ $1.5 \mathrm{~mm}$ were used in shape memory performances. First, the sample is heated to programming temperature $T_{\text {prog }}\left(80^{\circ} \mathrm{C}\right)$ and deformed applying $2 \mathrm{~N}$ force. Once the sample has been stretched, $\varepsilon_{m}$, the next stage is to cool it to below transition temperature $T_{\text {low }}\left(-20^{\circ} \mathrm{C}\right)$ in order to fix the temporary shape. Once the sample is unloaded, the deformation of the sample is $\varepsilon_{u}$. The shape-memory effect is triggered by heating the sample to a temperature above the transition temperature. The heating rate during shape recovery was $4^{\circ} \mathrm{C} \cdot \mathrm{min}^{-1}$. The amount of non-recoverable deformation at the end of programming is $\varepsilon_{p}$. The fixing $\left(R_{f}\right)$ and recovery $\left(R_{r}\right)$ ratios were calculated for each sample using Eqs. (1) and (2) ${ }^{16}$.

$$
\begin{gathered}
R_{f}(\%)=\frac{\varepsilon_{u}}{\varepsilon_{m}} \\
R_{r}(\%)=\frac{\varepsilon_{m}-\varepsilon_{p}}{\varepsilon_{m}}
\end{gathered}
$$


a)

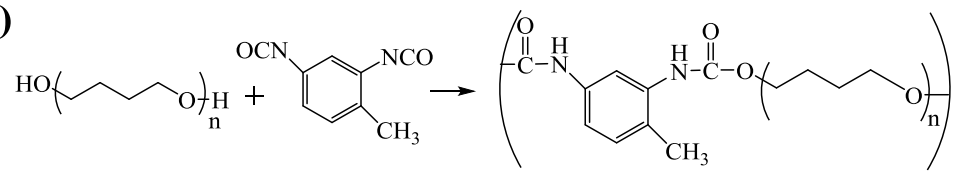

b)

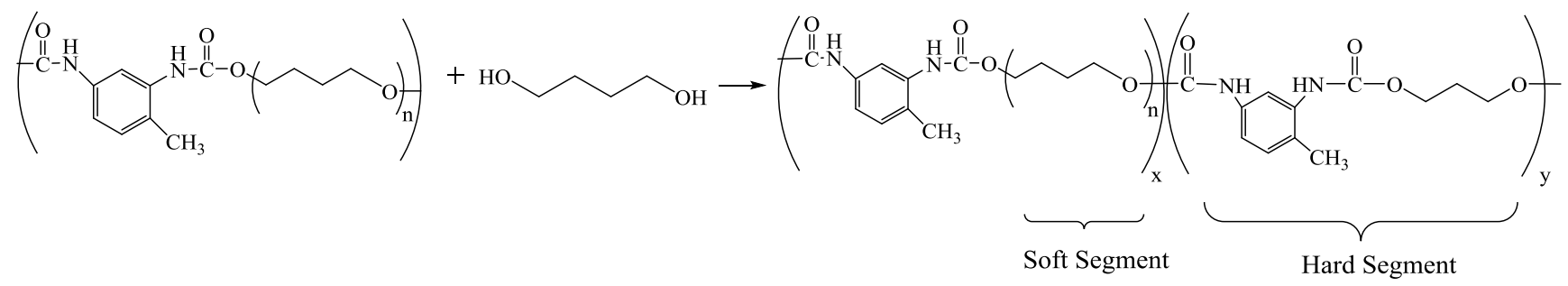

Figure 7. Synthesis route for toluene 2,4-diisocyanate (TDI) based polyurethanes: a) first step, b) second step.

\section{Conclusions}

In this work, shape memory polyurethanes (SMPUs) have been successfully synthetized by a two-step polymerization. Polyurethane samples display two-stage degradation showing good thermal stability with initial decomposition temperatures higher than $280^{\circ} \mathrm{C}$. Moreover, the glass transition temperatures were measured by DSC and DMTA. Both methods indicate that the glass transition temperature increase with the hard segment content, suggesting that reaction procedure was appropriate.

Finally, shape memory behavior of the synthetized polyurethanes was qualitatively and quantitatively evaluated. The qualitative evaluation demonstrates promoted shape memory response for all samples. At the same time, the quantitative analysis using TMA show that all the SMPUs samples are characterized by fixity ratios higher than $87 \%$ and recovery ratios near $99 \%$.

\section{Acknowledgments}

The authors would like to acknowledge Government of La Rioja and the Footwear
Technology Center of La Rioja for the financial support.

\section{Author Contributions}

M.Sáenz-Pérez realized the experiments and wrote the main paper. J.M. Laza, J. GarcíaBarrasa, L.M. León and J.L. Vilas supervised the project.

\section{Conflicts of Interest}

The authors declare no conflict of interest.

\section{References}

1. Lendlein, A. \& Kelch, S. Shape-Memory Polymers. Angew. Chemie Int. Ed. 2002, 41, 2034-2057.

2. Zhang, W., Chen, L. \& Zhang, Y. Surprising shape-memory effect of polylactide resulted from toughening by polyamide elastomer. Polymer (Guildf). 2009, 50,1311-1315.

3. Hu, J., Meng, H., Li, G. \& Ibekwe, S. I. A review of stimuli-responsive polymers for smart textile applications. Smart Mater. Struct. 2012, 21, 53001.

4. Peponi, L. et al. Synthesis and characterization of PCL-PLLA polyurethane 
with shape memory behavior. Eur. Polym. J. 2013, 49, 893-903.

5. Serrano, M. C. \& Ameer, G. A. Recent insights into the biomedical applications of shape-memory polymers. Macromol. Biosci. 2012, 12, 1156-71.

6. Huang, W. M. et al. Shaping tissue with shape memory materials. Adv. Drug Deliv. Rev. 2013, 65, 515-535.

7. Chang, Z. et al. Synthesis and properties of segmented polyurethanes with triptycene units in the hard segment. Polymer (Guildf). 2013, 54, 6910-6917.

8. Prisacariu, C., Scortanu, E., Coseri, S. \& Agapie, B. Effect of Soft Segment Polydispersity on the Elasticity of Polyurethane Elastomers. Ind. Eng. Chem. Res. 2013, 52, 2316-2322.

9. Trovati, G., Sanches, E. A., Neto, S. C., Mascarenhas, Y. P. \& Chierice, G. O. Characterization of polyurethane resins by FTIR, TGA, and XRD. J. Appl. Polym. Sci. 2010, 115, 263-268.

10. Liu, N. et al. The effects of the molecular weight and structure of polycarbonatediols on the properties of waterborne polyurethanes. Prog. Org. Coatings. 2015, 82, 46-56 (2015).

11. Yang, J. H., Chun, B. C., Chung, Y.-C. \& Cho, J. H. Comparison of thermal/mechanical properties and shape memory effect of polyurethane block-copolymers with planar or bent shape of hard segment. Polymer (Guildf). 2003, 44, 3251-3258.

12. Lin, J. R. \& Chen, L. W. Study on shapememory behavior of polyether-based polyurethanes. II. Influence of soft-segment molecular weight. J. Appl. Polym. Sci. 1998, $69,1575-1586$.

13. Fritzsche, N. \& Pretsch, T. Programming of Temperature-Memory Onsets in a Semicrystalline Polyurethane Elastomer. Macromolecules. 2014, 47, 5952-5959.

14. Pieczyska, E. A. et al. Thermomechanical properties of polyurethane shape memory polymer-experiment and modelling. Smart Mater. Struct. 2015, 24, 045043.

15. Saralegi, A., Gonzalez, M. L., Valea, A., Eceiza, A. \& Corcuera, M. A. The role of cellulose nanocrystals in the improvement of the shape-memory properties of castor oilbased segmented thermoplastic polyurethanes. Compos. Sci. Technol. 2014, 92, 27-33.

16. Axpe, E. et al. Connecting free volume with shape memory properties in noncytotoxic gamma-irradiated polycyclooctene. J. Polym. Sci. Part B Polym. Phys. 2015, 53, 10801088.

(C) 2015 by the authors; licensee MDPI, Basel, Switzerland. This article is an open access article distributed under the terms and conditions defined by MDPI AG, the publisher of the Sciforum.net platform. Sciforum papers authors the copyright to their scholarly works. Hence, by submitting a paper to this conference, you retain the copyright, but you grant MDPI AG the non-exclusive and unrevocable license right to publish this paper online on the Sciforum.net platform. This means you can easily submit your paper to any scientific journal at a later stage and transfer the copyright to its publisher (if required by that publisher). (http://sciforum.net/about). 